\title{
Evaluation of Attractiveness and Volatile Profiling of Food Baits for Monitoring of Stored Product Pests in Paddy
}

\author{
M. Sathiyaseelan, J. Jayaraj, M. Shanthi and K. Sujatha ${ }^{1}$ \\ Department of Agricultural Entomology, ${ }^{1}$ Department of Seed Science \& Technology, \\ Agricultural College and Research Institute, Madurai-625 104, India \\ E-mail: sathiyaseelanm1998@gmail.com
}

\begin{abstract}
Food baits are one of the strategies for monitoring and mass trapping of the stored product insects. Based on this principle, a study was conducted at central farm storage godown, Agricultural College and Research Institute, Madurai during March-April, 2021 by placing wheat flour, sorghum flour, pearl millet flour, rice flour, cracked corn, crushed groundnut, rice bran + rice flour as luring materials. Observations on trapped adult insects were taken on 25 days after placement of bait traps. Amongst the baits tested, wheat flour, cracked sorghum, pearl millet flour were the most attractive for stored grain pests of paddy. Wheat flour attracted $21.01 \%$ of Angoumois grain moth, Sitotroga cerealella and $13.38 \%$ of rice weevil, Sitophilus oryzae. Cracked sorghum registered attraction of $10.93 \%$ lesser grain borer, Rhyzopertha dominica and $13.10 \%$ of red flour beetle, Tribolium spp. Pearl millet flour attracted $11.65 \%$ of saw-toothed grain beetle, Oryzaephilus surinamensis. These effective baits were also test verified through four-arm olfactometer and found the highest orientation in the arm containing wheat flour by attracting S. oryzae, Tribolium spp. and $R$. dominica of 43.19, 39.61 and $37.41 \%$ respectively which possessed nonane, undecane, 3-octen-1ol, butanal and pentanal volatile compounds. Therefore, the wheat flour may be exploited as an effective bait material for monitoring and mass trapping of $S$. cerealella, $R$. dominica, Tribolium spp. and $O$. surinamensis in storage godowns of paddy.
\end{abstract}

Keywords: Bait traps, Olfactometer, Rice godown, Stored product insects, Wheat flour, Volatile compounds

Rice is one of the most important food crops for more than half of the world's population. Losses in storage due to insects greatly influence food availability. Most commonly the insects, birds, mites, fungi, rodents and moisture are the major problems in storage godowns causing damage to rice. Stored product insects particularly adult beetles, due to their harbourage seeking behaviour, seek refuge in cracks and crevices of warehouse and storage godown. Lesser grain borer, Rhyzopertha dominica (Fabricius) (Bostrichidae; Coleoptera), rice weevil, Sitophilus oryzae (L.) (Curclionidae; Coleoptera), red flour beetle, Tribolium spp. (Tenebrionidae; Coleoptera), and Angoumois grain moth, Sitotroga cerealella (Olivier) (Gelechidae; Lepidoptera) are the most destructive insects which are found in stored cereals, flour mills, and storage godowns/warehouses (Kim et al 2010, Ahmed and Raza 2010, Duehl et al 2011, Ahmad et al 2013). Food attractant and repellent are used to manage several stored product insects (Mohan and Fields 2002). The food bait material used for detecting stored product insects may be a liquid or solid. Volatile chemical olfactory cues play an important role as attractants and diversity of substances such as kairomone can be exploited for the management of stored product insects (Mahroof and Phillips 2007). The granary weevil, Sitophilus granarius is the most widely studied storage insect species concerning its response to kairomone, with its reaction to crushed seed or whole seed (Rietdorf and Steidle 2002). Pheromones are normally species specific and a lot of insect species feed on one food stuff due to the volatiles from this food attract more than one species (Collins et al 2007). Combining food volatiles and pheromone odour can increase the pitfall traps efficiency against Sitophilus spp. (Likhayo and Hodges 2000, Wakefield et al 2005). Accordingly, the present study is aimed to exploit easily available, cheap, effective and attractive bait sources for the management of major pests in stored paddy.

\section{MATERIAL AND METHODS}

Trapping efficiency of different food baits: The test was conducted at Central Farm storage godown (14.5 x $6.5 \times 3.5$ $\mathrm{m})$, Agricultural college and Research Institute, Madurai. The crushed grains and flours of wheat, sorghum, maize, groundnut, rice, rice bran and pearl millet were taken and filled in the polythene receptacles of probe trap-like structures, which contain rustproof silver metal hollow cylinders $(23 \times 5 \mathrm{~cm})$ with 280 evenly spaced $4 \mathrm{~mm}$ holes. One end of the trap was closed by a removable cap. The bait traps were inserted in the interspaces between the bags arranged in a stack and the trap was filled with $50 \mathrm{~g}$ of bait material. The insects were crawled by orientation through the $4 \mathrm{~mm}$ hole and dropped into the bottom part of the receptacle. 
The trap catches were recorded for 25 days. The number of insects caught in control (without bait material) was compared with the number of insects caught in the other treatments. The attraction index was calculated by using the formula (Smith et al 1993).

$$
\text { Attraction Index }=\frac{T-C}{N} \times 100
$$

Where, N- Number of insects attracted in treatment, CNumber of insects trapped in the control, N-Total number of individuals

Olfactometer bioassay: To study the chemoreception and attraction an experiment was conducted using specially designed four-star shaped olfactometer made of plastic (25 $\mathrm{x}$ $25 \times 11.5 \mathrm{~cm}$ ), with a $2.5 \mathrm{~cm}$ diameter opening in four corners. Each corner had a small tube, through which air could go from the arena along the central tube. The corner tubes were linked to Tygon tubing with four different gas washing bottles, all filled with a $10 \mathrm{~g}$ of olfactory stimulus (food attractants). This set-up provided the insects to recognize the olfactory cues of the food attractants. Air was blown to each of the four arms by the pump. The odour residue in the arena of the tubes was cleaned with $70 \%$ ethanol (Arnold et al 2012). The test adults viz., $R$. dominica, Tribolium spp. and S. oryzae were starved for $24 \mathrm{~h}$ in Petri plates before the commencement of olfactory bioassay. Twenty unsexed adults were released in the centre of the olfactometer $(7 \mathrm{~mm}$ hole) and it was covered with cloth to minimise the phototactic response of insects. After 10 minutes, the location of the insects was observed (Ukeh et al 2010). Three different best odour/volatile sources were used to observe the response of $R$. dominica, Tribolium spp., S. oryzae. Each treatment was replicated 10 times.

\section{Volatile Profiling of Food Baits in GC-MS/MS}

Sample preparation: Spectroscopic analysis of food baits was done with Gas chromatograph-mass spectrometer (GC$\mathrm{MS} / \mathrm{MS}$ ) to find out the chemical cues. For this purpose, a fresh sample of the selected food bait was dried and ground into powder. Samples (10 g each) were extracted with $30 \mathrm{ml}$ of methanol in an ultrasonic bath for $30 \mathrm{~min}$ and filtered through a $0.45 \mu \mathrm{m}$ polyvinylidene fluoride syringe filter for GC-MS/MS analysis (Kim et al 2020)

GC- MS/MS analysis: The methanol extract was characterized using GC- MS/MS (GC 2010 plus, GCMS - TQ 8040 SHIMADZU), in Central Instrumental Laboratory, Department of Agricultural Entomology, Agricultural College and Research Institute, Madurai. The compounds were separated on the capillary column (Rxi ${ }^{\circledR}-5$ Sil MS). The carrier gas was helium (purity percentage $>99.99 \%$ ) with a column flow rate of $1 \mathrm{ml} / \mathrm{min}$ and the injection was done in split less mode. The oven temperature was scheduled at $110^{\circ} \mathrm{C}$, which was constantly increased to $150^{\circ} \mathrm{C}$ at a rate of $10^{\circ} \mathrm{C} / \mathrm{min}$ and held for $5 \mathrm{~min}$, then increased to $200^{\circ} \mathrm{C}$ at a rate of $10^{\circ} \mathrm{C} / \mathrm{min}$. After holding $20 \mathrm{~min}$ again, it was finally increased to $240^{\circ} \mathrm{C}$ at a rate of $10^{\circ} \mathrm{C} / \mathrm{min}$ and held for $5 \mathrm{~min}$. The MS was operated in electron ionization (EI) mode at 70 $\mathrm{eV}$, ion source temperature $200^{\circ} \mathrm{C}$, interface temperature was $230^{\circ} \mathrm{C}$ and scan range was $45-600 \mathrm{~m} / \mathrm{z}$. The solvent cut time was $3 \mathrm{~min}$. Each sample was allowed to run for 30 minutes. The spectrum of the unknown volatile compounds was identified by the NIST 17 (National Institute of Standards and Technology) MS library database. The obtained compounds were tabulated along with the per cent area of the peaks and retention time (RT).

Statistical analysis: The attraction index and the difference in the behavioural response/orientation of the beetles were analysed using Completely Randomized Design by using Duncan's Multiple Range Test (DMRT) with IBM SPSS 22.0 software.

\section{RESULTS AND DISCUSSION}

The attraction of $S$. cerealella $R$. dominica, Tribolium spp., S. oryzae, O. surinamensis adults varied with food attractants (Table 1). Among the food bait attractants tested, wheat flour (21.01\%) was the most attractive to S. cerealella followed by pearl millet flour, rice bran and the least attraction was noticed in crushed groundnut (4.62\%). For R. dominica, the cracked sorghum was highly attractive (10.93\%) followed by pearl millet flour, cracked corn and the least attraction with rice flour $(4.04 \%)$. Cracked sorghum (13.10\%) was highly attractive to Tribolium spp. followed by sorghum flour, wheat flour and the least attraction was in cracked corn (3.35\%). The attraction of $S$. oryzae to wheat flour and sorghum flour was high (13.27 and $11.67 \%$ respectively) followed by cracked sorghum, pearl millet flour and crushed groundnut. Pearl millet flour was highly attractive for 0 . surinamensis $(11.65 \%)$ followed by rice bran $(7 \%)$, sorghum flour, cracked sorghum. wheat flour and the least attraction with cracked corn $(2.10 \%)$. Wheat flour attracted more S. oryzae $(13.38 \%)$ compared to other food attractants. Earlier studies indicated that larger grain borer, Prostephanus truncatus and $R$. dominica had a positive attraction towards cereal host odour (Bashir et al 2001, Edde and Phillips 2006). The cracked wheat alone attracted Sitophilus zeamais six times more than S. oryzae (Likhayo and Hodges 2000). The maximum attraction of $R$. dominica was due to some odour/volatile produced by cracked sorghum (10.93\%) and S. cerealella to wheat flour $(21.01 \%)$ and $O$. surinamensis to pearl millet flour (11.65\%). Ahmad et al (2013) who reported that $R$. dominica had been attracted more to wheat flour. The comparative efficacy of different food baits to various storage 
insect pests revealed that the wheat flour was more attractive to $S$. cerealella, $S$. oryzae and $O$. surinamensis sorghum flour/ cracked sorghum to $R$. dominica, $S$. oryzae, Tribolium spp. and $O$. surinamensis and the pearl millet flour to $S$. cerealella, R. dominica, S. oryzae and $O$. surinamensis (Fig. 1). The total attraction index of wheat flour $>$ sorghum flour $>$ cracked sorghum $>$ pearl millet flour was found to be $56.60,45.73,45.23$ and $43.71 \%$ respectively (Table 1 ). Proving that wheat, sorghum and pearl millet flours were effective attractants to different stored grain pests of paddy.

Olfactometer bioassay: Olfactometer bioassay revealed the significant differences in the orientation behaviour of $R$. dominica, Tribolium spp. and S. oryzae towards food bait attractants in a four-armed olfactometer. Among the three food baits tested, the highest attraction $(43.19 \%)$ of S. oryzae was in the arm containing wheat flour followed by Tribolium spp. and $R$. dominica. Sorghum flour attracted S. oryzae, Tribolium spp. and $R$. dominica. The least attraction was in pearl millet flour with $21.83,18.07,17.62 \%$ of $S$. oryzae, Tribolium spp., R. dominica, respectively (Fig. 2).

The orientation response of $R$. dominica to wheat volatiles in two-arm olfactometer bioassay was proved by Dowdy et al (1993). However, in our study a four-arm olfactometer bioassay, multi choice test a greater number of S. oryzae $(43.19 \%)$, R. dominica $(37.41 \%)$ and Tribolium spp. (39.61\%) was attracted to the test arm containing wheat flour. $R$. dominica spent more time in the olfactometer arm containing de-oiled groundnut odour/volatile compared to the arm contained maize or wheat odour/volatile (Bashir 2000). In the present study also $R$. dominica, Tribolium spp. and

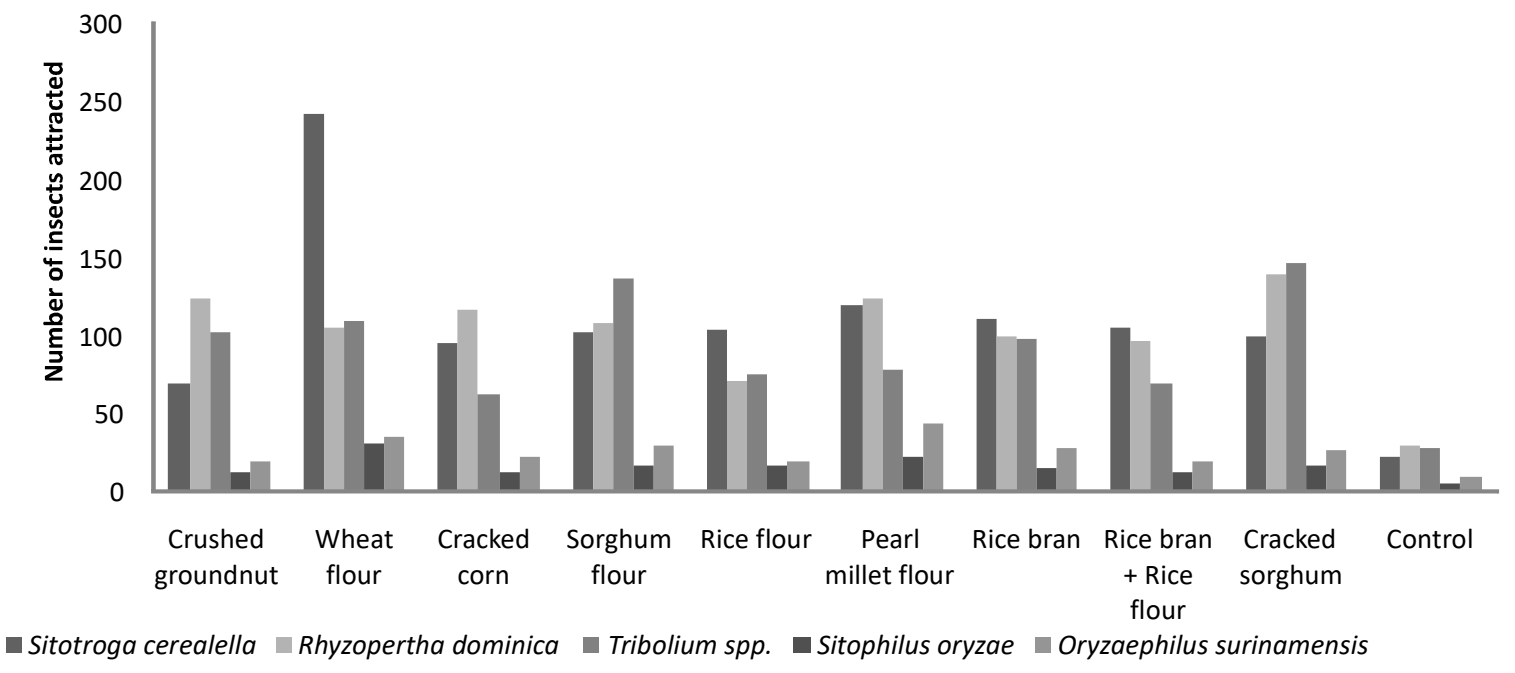

Fig. 1. Response of stored product insects to various food attractants in bait traps

Table 1. Comparative response of stored product insects of paddy to various food bait attractants

\begin{tabular}{|c|c|c|c|c|c|c|}
\hline \multirow[t]{2}{*}{ Attractants } & \multicolumn{5}{|c|}{ Relative attraction index (\%) } & \multirow[t]{2}{*}{ Total attraction index (\%) } \\
\hline & $\begin{array}{c}\text { Sitotroga } \\
\text { cerealella }\end{array}$ & $\begin{array}{c}\text { Rhyzopertha } \\
\text { dominica }\end{array}$ & Tribolium spp & $\begin{array}{c}\text { Sitophilus } \\
\text { oryzae }\end{array}$ & $\begin{array}{l}\text { Oryzaephilus } \\
\text { surinamensis }\end{array}$ & \\
\hline Crushed groundnut & $4.62^{9}$ & $9.31^{\mathrm{b}}$ & $8.07^{d}$ & $2.59^{\mathrm{de}}$ & $2.99^{\text {cd }}$ & 27.58 \\
\hline Wheat flour & $21.01^{\mathrm{a}}$ & $7.42^{\mathrm{e}}$ & $8.93^{c}$ & $13.27^{\mathrm{a}}$ & $5.97^{\mathrm{b}}$ & 56.60 \\
\hline Cracked corn & $7.09^{f}$ & $8.48^{\circ}$ & $3.35^{\mathrm{h}}$ & $5.51^{\text {bcd }}$ & $2.10^{\text {de }}$ & 26.53 \\
\hline Sorghum flour & $7.50^{\mathrm{e}}$ & $7.75^{d}$ & $11.94^{\mathrm{b}}$ & $11.67^{\mathrm{a}}$ & $6.86^{b}$ & 45.73 \\
\hline Rice flour & $7.44^{\mathrm{e}}$ & $4.04^{9}$ & $5.21^{\dagger}$ & $7.13^{\mathrm{bc}}$ & $1.79^{\mathrm{de}}$ & 25.61 \\
\hline Pearl millet flour & $9.27^{b}$ & $9.34^{\mathrm{b}}$ & $5.36^{f}$ & $8.09^{b}$ & $11.65^{\mathrm{a}}$ & 43.71 \\
\hline Rice bran & $8.35^{\mathrm{c}}$ & $6.92^{f}$ & $7.66^{\mathrm{e}}$ & $7.12^{\mathrm{bc}}$ & $7.16^{\mathrm{b}}$ & 37.22 \\
\hline Rice bran + Rice flour & $7.97^{\mathrm{d}}$ & $6.66^{f}$ & $4.39^{9}$ & $4.21^{\mathrm{cd}}$ & $3.45^{\mathrm{c}}$ & 26.68 \\
\hline Cracked sorghum & $7.12^{f}$ & $10.93^{\mathrm{a}}$ & $13.10^{\mathrm{a}}$ & $8.10^{b}$ & $5.98^{b}$ & 45.23 \\
\hline Control & $0.00^{\mathrm{h}}$ & $0.00^{\mathrm{h}}$ & $0.00^{i}$ & $0.00^{\circ}$ & $0.00^{\circ}$ & 0.00 \\
\hline SEd & 0.1177 & 0.1504 & 0.1542 & 1.4152 & 0.6018 & - \\
\hline
\end{tabular}

Mean followed by the same letter $(\mathrm{s})$ in a column are not significantly different by DMRT $(\mathrm{P}=0.05)$ 
S. oryzae spent more time in the arm containing wheat flour. Vijay et al (2020) reported that the highest orientation $(50.5 \%)$ of $S$. oryzae females and males were recorded towards sorghum in 20 minutes after release. In present study the orientation of $S$. oryzae towards sorghum flour $(30.12 \%)$ was within 10 minutes after release. In the current study, the baits were arranged in the order of the number of visits or entries towards the wheat flour $(37.41 \%)$, sorghum flour $(28.75 \%)$ and pearl millet flour $(17.62 \%)$, which are comparable with earlier works. Behavioural response of $R$. dominica to host plant (maize grain and winter wheat grains) bioassay indicated that both male and female $R$. dominica attracted to maize and wheat grain than the control (Ukeh and Umoetok 2007).

GC-MS/MS: The separation of the volatile compound was obtained using the $R_{x} i-5$ Sil MS capillary column. There were over 89,85 and 80 peaks on the chromatogram of wheat, sorghum and pearl millet respectively (Fig. 3). The major attractive volatile compounds present in the three flours analyzed were hexanol, butyric acid, propionic acid, nonane, undecane, 3-octen-1-ol, hexanal, nonanal, octanal, butanal and hexanoic acid (Table 2).

The food bait attraction to $S$. cerealella and $S$. oryzae in wheat flour may be due to the presence of volatile compounds like nonane, undecane, butanol and 3-octen-1-ol which were found in the present analytical study. E-2nonenal and 4-ethylacetophenone compounds induced positive response from $O$. surinamensis, Sitophilus granarius and Cryptolestes ferrugineus in accordance with earlier findings (Collins et al 2007, Dooley et al 2018). Hexanoic acid, 2-phenylethanol and E-3-octen-2-one had elicited a response for $O$. surinamensis and $S$. granarius (Collins et al 2007). The present investigation corroborates with other studies where the chemical compounds like hexanol and butyric acid were found to be the attractive volatile compounds present in sorghum, which resulted the orientation of $R$. dominica and Tribolium spp. (Giliomee et al 2007, Collins et al 2007).

Hexanal, nonanal, undecane, octanal, butanal and hexanoic acid were identified as attractive compounds (Giliomee et al 2007, Collins et al 2007, Dooley et al 2018) which are responsible for greater catch of $O$. surinamensis. Different doses of benzaldehyde and aliphatic aldehyde have been tested for $O$. surinamensis and $O$. Mercator observed positive response of both species. The present investigation corroborates with other studies that hexanol and butyric acid were the attractive volatile compounds present in sorghum flour which attracted $R$. dominica and Tribolium spp. . Balakrishnan et al (2017) . reported a related findings that undecane, octanal, 1-hexen-3-ol, 2-heptanone, ethyl hexanoate and hexanoic acid had elicited the strongest electroantennographic (EAG) responses to Tribolium castaneum. Adults of Callosobruchus sinensis showed preferential behaviour towards benzaldehyde and 2-hexanal (Wang et al 2020) while Callosobruchus maculatus was attracted by 3-octanol, linalool oxide, 3-octanone, nonanal and 1-octanol (Adhikary et al 2015). The results of present study is also comparable with the reports of Germinara et al (2008) that Sitophilus oryzae and S. granarius showed repellent effects towards propionic acid. Appalasamy et al (2021) reported that octadecanoic acid, pentadecanoic acid and cis- Vaccenic acid acted as repellent and insecticidal activity against termites, Macrotermes carbonarius and cockroaches, Periplaneta americana, which are in line with

Table 2. Volatile profiles of food bait attractants

\begin{tabular}{lccc}
\hline Volatile compounds & \multicolumn{3}{c}{ Peak area (\%) } \\
\cline { 2 - 4 } & Wheat & Sorghum & Pearl millet \\
\hline 3-Hexanol & - & $0.09 \pm 0.0008$ & - \\
1-Butanol & $0.25 \pm 0.004$ & - & - \\
3-Octen-1-ol & $0.24 \pm 0.006$ & & $0.26 \pm 0.002$ \\
7-Octen-4-one & - & $0.12 \pm 0.0003$ & $0.78 \pm 0.005$ \\
1-Octanal & - & - & - \\
Pentanal & $0.32 \pm 0.0005$ & - & $0.58 \pm 0.014$ \\
Hexanal & - & - & $0.24 \pm 0.001$ \\
Butanal & - & - & $1.55 \pm 0.008$ \\
Nonanal & - & - & $0.73 \pm 0.009$ \\
Undecane & $1.73 \pm 0.029$ & - & - \\
Nonane & $0.3 \pm 0.005$ & - & $0.23 \pm 0.002$ \\
Propionic acid & - & $0.12 \pm 0.001$ & - \\
Butyric acid & - & $0.10 \pm 0.001$ & $0.57 \pm 0.001$ \\
Hexanoic acid & - & - & $20.36 \pm 0.512$ \\
n-Hexadecanoic acid & $12.65 \pm 0.022$ & $15.42 \pm 0.181$ & - \\
cis-Vaccenic acid & - & - & - \\
\hline & & &
\end{tabular}

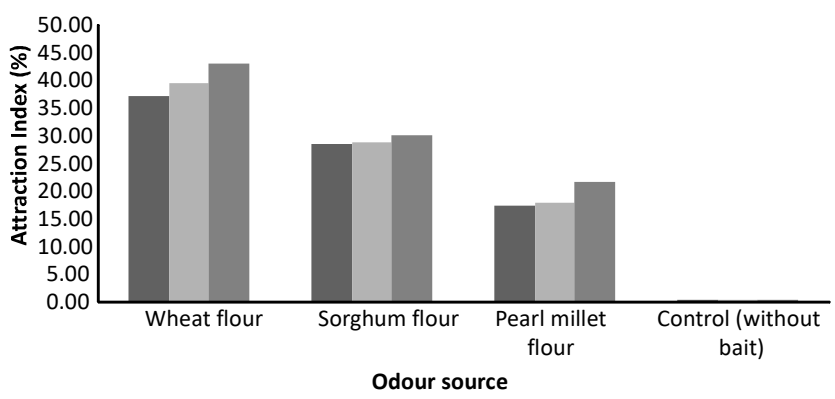

Fig. 2. Behavioural/Orientation response of Rhyzopertha dominica, Tribolium spp. and Sitophilus oryzae to various food attractants 

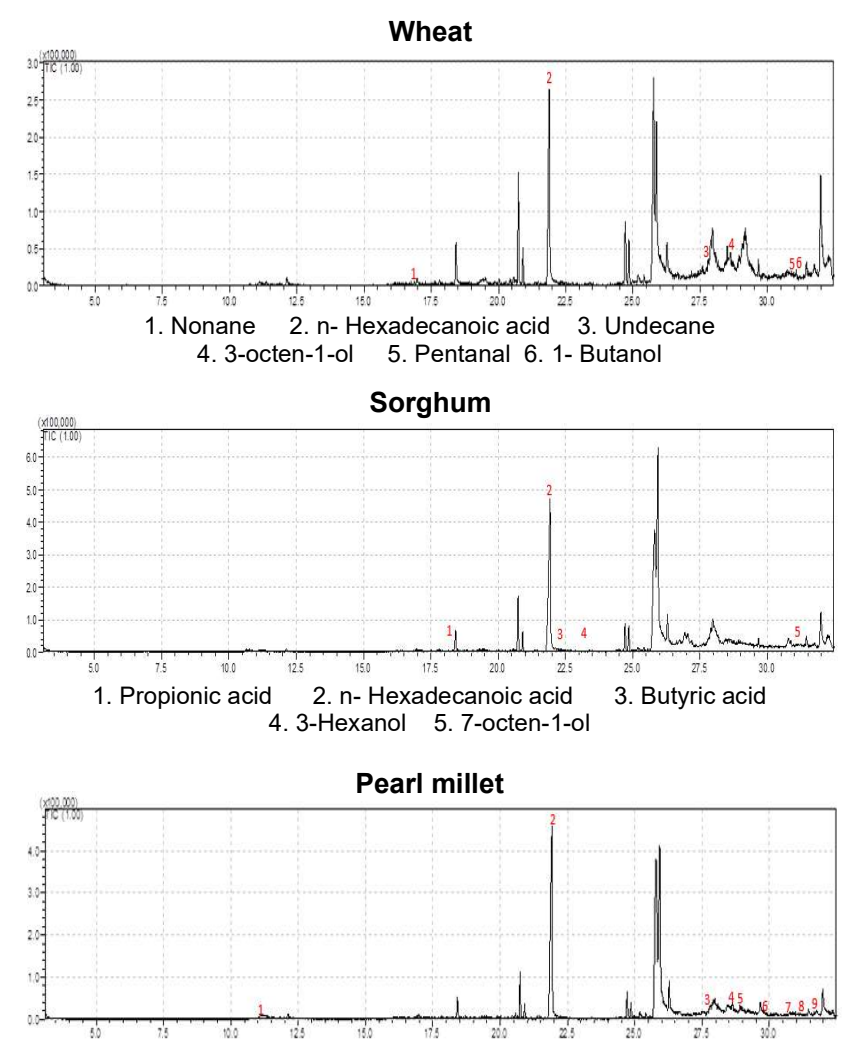

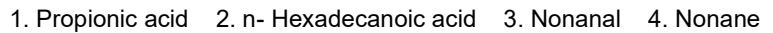
$\begin{array}{lll}\text { 5. Hexanal 6. 1-octanal 7. Butanal } & \text { 8. 7-octen-4-one 9. Hexanoic acid }\end{array}$

Fig. 3. GC MS/MS volatile profile of wheat, sorghum and pearl millet

our investigation. In study, the cis-Vaccenic acid present in rice bran $(59.06 \%)$, so attraction per cent was very low towards this bait. The n-Hexadecanoic acid was present in a lower amount in wheat $(12.65 \%)$, had exhibited very high attraction per cent in wheat compared to others (Table 1 and 2).

\section{CONCLUSION}

This study emphasized the attraction efficiency of different food baits to various storage insect pests that can be used to develop a multi-species lure for the control of stored grain pests. An effective food bait lures can be formulated using multiple millet-based flours like wheat flour, sorghum flour/cracked sorghum and pearl millet flour and that can be further exploited for monitoring and mass trapping of storage insect pests in rice godowns.

\section{REFERENCES}

Adhikary P, Mukherjee A and Barik A 2015. Attraction of Callosobruchus maculatus (F.) (Coleoptera: Bruchidae) to four varieties of Lathyrus sativus $L$. seed volatiles. Bulletin of Entomological Research 105 (2): 187-201.

Ahmad F, Ridley AW, Daglish GJ, Burrill PR and Walter GH 2013. Response of Tribolium castaneum and Rhyzopertha dominica to various resources, near and far from grain storage. Journal of Applied Entomology 137(10): 773-781.

Ahmad F, Ridley AW, Daglish GJ, Burrill PR and Walter GH 2013. Response of Tribolium castaneum and Rhyzopertha dominica to various resources, near and far from grain storage. Journal of Applied Entomology 137(10): 773-781.

Ahmed S and Raza A 2010. Antibiosis of physical characteristics of maize grains to Sitotroga cerealella (Oliv.) (Gelechiidae: Lepidoptera) in free choice test. Pakistan Journal of Life and Social Sciences 8(2): 142-147.

Appalasamy S, Diyana MA, Arumugam N and Boon JG 2021. Evaluation of the chemical defense fluids of Macrotermes carbonarius and Globitermes sulphureus as possible household repellents and insecticides. Scientific Reports 11(1): 1-11.

Arnold SE, Stevenson PC and Belmain SR 2012. Odour-mediated orientation of beetles is influenced by age, sex and morph. Public Library of Science One 7(11): e49071.

Balakrishnan K, Holighaus G, Weißbecker B and Schütz S 2017. Electroantennographic responses of red flour beetle Tribolium castaneum Herbst (Coleoptera:Tenebrionidae) to volatile organic compounds. Journal of Applied Entomology 141(6): 477-486.

Bashir T 2000. Pheromone communication and host-finding behaviour of Rhyzopertha dominica (F.) (Coleoptera: Bostrichidae) Doctoral dissertation, University of Greenwich (UK): 205

Bashir T, Birkinshaw LA, Hall DR and Hodges RJ 2001. Host odours enhance the responses of adult Rhyzopertha dominica to male-produced aggregation pheromone. Entomologia Experimentalis et Applicata 101(3): 273-280.

Collins LE, Bryning GP, Wakefield ME, Chambers $\mathrm{J}$ and Cox PD 2007. Progress towards a multi-species lure: identification of components of food volatiles as attractants for three storage beetles. Journal of Stored Products Research 43(1): 53-63.

Dooley M, Peel AD and Wakefield M 2018. The responses of Tribolium castaneum to wheat germ oil and fungal produced volatiles. Julius-Kühn-Archiv 463: 129-138.

Dowdy AK, Howard RW, Seitz L M and McGaughey W H 1993. Response of Rhyzopertha dominica (Coleoptera: Bostrichidae) to its aggregation pheromone and wheat volatiles. Environmental Entomology 22(5): 965-970.

Duehl AJ, Cohnstaedt LW, Arbogast RT and Teal PEA 2011. Evaluating light attraction to increase trap efficiency for Tribolium castaneum (Coleoptera: Tenebrionidae). Journal of Economic Entomology 104(4): 1430-1435.

Edde PA and Phillips TW 2006. Potential host affinities for the lesser grain borer, Rhyzopertha dominica: behavioral responses to host odors and pheromones and reproductive ability on non-grain hosts. Entomologia Experimentalis et Applicata 119(3): 255-263.

Germinara GS, De Cristofaro A and Rotundo G 2008. Behavioral responses of adult Sitophilus granarius to individual cereal volatiles. Journal of Chemical Ecology 34(4): 523-529.

Giliomee JH, Venter E and Wohlfarter M 2007. Mediterranean black fig fly, Silba adipata McAlpine (Diptera: Lonchaeidae), recorded from South Africa. African Entomology 15(2): 383-384.

Kim BR, Kim HM, Jin CH, Kang SY, Kim JB, Jeon YG and Han AR 2020. Composition and antioxidant activities of volatile organic compounds in radiation-bred Coreopsis cultivars. Plants 9(6): 717.

Kim SI, Yoon JS, Jung JW, Hong KB, Ahn YJ, and Kwon HW 2010. Toxicity and repellency of origanum essential oil and its components against Tribolium castaneum (Coleoptera: Tenebrionidae) adults. Journal of Asia-Pacific Entomology 13(4): 369-373.

Likhayo PW and Hodges RJ 2000. Field monitoring Sitophilus zeamais and Sitophilus oryzae (Coleoptera: Curculionidae) 
using refuge and flight traps baited with synthetic pheromone and cracked wheat. Journal of Stored Products Research 36(4): 341-353.

Mahroof RM and Phillips TW 2007. Orientation of the cigarette beetle, Lasioderma serricorne (F.) (Coleoptera: Anobiidae) to plant-derived volatiles. Journal of Insect Behavior 20(1): 99115.

Mohan S and Fields PG 2002. A simple technique to assess compounds that are repellent or attractive to stored-product insects. Journal of Stored Products Research 38(1): 23-31.

Rietdorf $\mathrm{K}$ and Steidle JL 2002. Was Hopkins right? Influence of larval and early adult experience on the olfactory response in the granary weevil Sitophilus granarius (Coleoptera, Curculionidae). Physiological Entomology 27(3): 223-227.

Smith CM, Khan ZR and Pathak MD 1993. Techniques for evaluating insect resistance in crop plants. CRC press. 170-171

Ukeh DA and Umoetok SBA 2007. Effects of host and non-host plant volatiles on the behavior of the Lesser Grain Borer, Rhyzopertha

Received 28 September, 2021; Accepted 19 January, 2022 dominica (Fab.). Journal of Entomology 4(6): 435-443.

Ukeh DA, Birkett MA, Bruce TJ, Allan EJ, Pickett JA and Mordue AJ 2010. Behavioural responses of the maize weevil, Sitophilus zeamais, to host (stored-grain) and non-host plant volatiles. Pest Management Science 66(1): 44-50.

Vijay S, Bhuvaneswari K, Baskaran V and Lisha JM 2020. Olfactometer studies of Sitophilus oryzae L. feeding on sorghum and split pulses. Journal of Entomology and Zoology Studies 8(4): 1239-1243

Wakefield ME, Bryning GP and Chambers J 2005. Progress towards a lure to attract three stored product weevils, Sitophilus zeamais Motschulsky, S. oryzae (L.) and S. granarius (L.) (Coleoptera: Curculionidae). Journal of Stored Products Research 41(2): 145-161.

Wang HM, BAI PH, Zhang J, Zhang XM, Qin HUI, Zheng HX and Zhang XH 2020. Attraction of bruchid beetles Callosobruchus chinensis (L.) (Coleoptera: Bruchidae) to host plant volatiles. Journal of Integrative Agriculture 19(12): 3035-3044 